\title{
Calculation of Radioactivity and Dose Rate of Activated Corrosion Products in Water-Cooled Fusion Reactor
}

\author{
Jingyu Zhang, Lu Li, Shuxiang He, and Yixue Chen \\ School of Nuclear Science and Engineering, North China Electric Power University, Beijing 102206, China \\ Correspondence should be addressed to Jingyu Zhang; poptnt@163.com
}

Received 27 May 2016; Accepted 19 July 2016

Academic Editor: Massimo Zucchetti

Copyright (C) 2016 Jingyu Zhang et al. This is an open access article distributed under the Creative Commons Attribution License, which permits unrestricted use, distribution, and reproduction in any medium, provided the original work is properly cited.

In water-cooled reactor, the dominant radioactive source term under normal operation is activated corrosion products (ACPs), which have an important impact on reactor inspection and maintenance. A three-node transport model of ACPs was introduced into the new version of ACPs source term code CATE in this paper, which makes CATE capable of theoretically simulating the variation and the distribution of ACPs in a water-cooled reactor and suitable for more operating conditions. For code testing, MIT PWR coolant chemistry loop was simulated, and the calculation results from CATE are close to the experimental results from MIT, which means CATE is available and credible on ACPs analysis of water-cooled reactor. Then ACPs in the blanket cooling loop of water-cooled fusion reactor ITER under construction were analyzed using CATE and the results showed that the major contributors are the short-life nuclides, especially Mn-56. At last a point kernel integration code ARShield was coupled with CATE, and the dose rate around ITER blanket cooling loop was calculated. Results showed that after shutting down the reactor only for 8 days, the dose rate decreased nearly one order of magnitude, which was caused by the rapid decay of the short-life ACPs.

\section{Introduction}

In the cooling loop of water-cooled reactor, the oxidation and corrosion of the metal material by water are inevitable, and part of the corrosion products will be activated under neutron irradiation and become radioactive, which are called activated corrosion products (ACPs). Some ACPs continuously decay and emit harmful gamma-rays even after shutdown of the reactor for a long time. According to the surveillance data from French PWR plants, more than 90\% of integrated dose under normal operation is due to ACPs [1], which means vital impact of ACPs on radiation protection. For the water-cooled fusion reactor, it is also necessary to research the formation mechanism and transport process of ACPs and to predict the variation and distribution of radioactivity and dose rate of ACPs, which is important to radiation shielding design, inspection, and maintenance as well as accident analysis of the reactor.

Because of the importance of ACPs, the relevant research was started since 1960s in PWR plants, and many codes have been developed [2], for example, CORA from EPRI, PACTOLE from CEA, CRUDTRAN from KAERI, and
MIGA-RT from BSA, which were widely used in ACPs analysis of PWR plants and showed good effect. For ACPs analysis of water-cooled fusion reactor, especially the International Thermonuclear Experimental Reactor (ITER) under construction, three codes were developed, which are PACTITER from CEA, TRACT from UKAEA, and CATE from NCEPU (North China Electric Power University) by the author. In the initial version of CATE, the model adopted is mainly based on the empirical coefficient method [3], which is simple but not universal for different operation condition. In the latest version of CATE, a three-node transport model was adopted, which is based on the theory that the main driving force for corrosion products transport is the temperature change of the coolant throughout the loop and the resulting change in metal ion solubility in the coolant [4], making CATE capable of theoretically simulating the variation and the distribution of ACPs and have a larger scope of application.

The basic theory and equations of the three-node transport model were described in the second section of this paper, and ACPs in MIT PWR coolant chemistry loop and ITER blanket cooling loop were calculated using the code CATE, respectively, in the third section and the fourth section. Then 


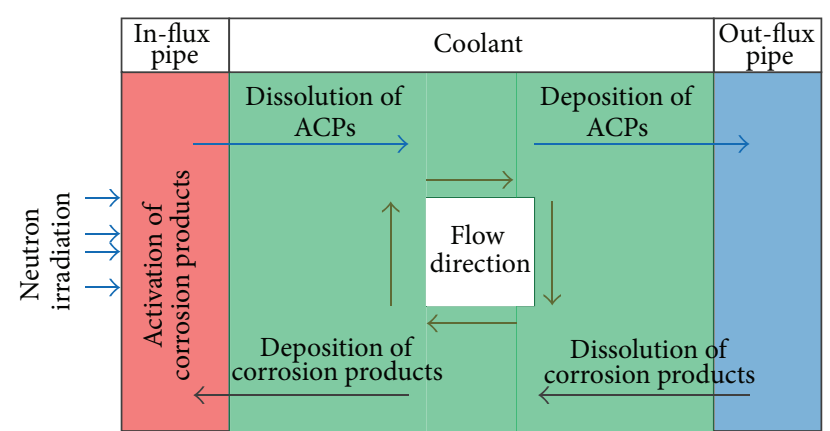

FIgURE 1: Transport process of ACPs in the cooling loop based on the three-node model.

the dose rate around ITER blanket cooling loop caused by ACPs was calculated using the point kernel integration code ARShield in the fifth section. In the last section, a comprehensive comment was presented.

\section{Description of the Three-Node Transport Model}

In the model, the cooling loop is divided into three nodes, which are the in-flux pipe, the coolant, and the out-flux pipe. The corrosion products transport between the nodes is by means of dissolution and deposition. Nickel ferrite is the main corrosion products in the cooling loop, and it shows an inverse solubility curve with temperature. As the coolant temperature changes around the cooling loop, the saturation status of the corrosion products in the coolant also changes. In the region of out-flux (e.g., the heat-exchanger), as the coolant temperature decreases, the soluble species become undersaturated, so that there is a driving force for the corrosion products on the pipe surface to dissolve into the coolant to restore a saturation concentration of corrosion products in the coolant. On the other hand, in the region of in-flux (e.g., the core in PWR or the blanket in fusion reactor), where the coolant temperature increases, the soluble species exist in a supersaturated state, so that there is a driving force for the soluble species to deposit on the pipe surface. Through this process, the corrosion products are transported from the out-flux pipe to the in-flux pipe.

In the region of in-flux, part of the corrosion products absorb neutrons and become ACPs. The ratio of ACPs to corrosion products on the pipe surface is larger than that in the coolant, so there is a net flow of ACPs from the pipe surface to the coolant by isotope exchange. In the region of out-flux, the ratio of ACPs to corrosion products in the coolant is larger than that on the pipe surface, so there is a net flow of ACPs from the coolant to the pipe surface. Through this process, ACPs are transported from the in-flux pipe to the out-flux pipe, which is described in Figure 1.

In brief, the three-node transport model is based on the theory that the main driving force for ACPs transport is the temperature change of the coolant throughout the loop and the resulting change in metal ion solubility in the coolant. So whether it is PWR temperature range $\left(280 \sim 320^{\circ} \mathrm{C}\right)$ or ITER temperature range $\left(140 \sim 180^{\circ} \mathrm{C}\right)$, the three-node transport model is all applicable.

In CATE, the corresponding equations are as follows:

$$
\begin{aligned}
\frac{d I_{m, 1}}{d t}= & f_{m, 1}\left(1-\alpha_{1}\right) \mathrm{CR}_{1} A_{1} \\
& +k_{m, 1}\left(\frac{I_{m, 2}}{V}-S_{m, 1}\right) A_{1}, \\
\frac{d I_{m, 2}}{d t}= & f_{m, 1} \alpha_{1} \mathrm{CR}_{1} A_{1}+f_{m, 3} \alpha_{3} \mathrm{CR}_{3} A_{3} \\
& -k_{m, 1}\left(\frac{I_{m, 2}}{V}-S_{m, 1}\right) A_{1} \\
& +k_{m, 3}\left(S_{m, 3}-\frac{I_{m, 2}}{V}\right) A_{3}-\omega \frac{\mathrm{Q}}{V_{\mathrm{CVCS}}} I_{m, 2},
\end{aligned}
$$

$$
\begin{aligned}
\frac{d I_{m, 3}}{d t}= & f_{m, 3}\left(1-\alpha_{3}\right) \mathrm{CR}_{3} A_{3} \\
& -k_{m, 3}\left(S_{m, 3}-\frac{I_{m, 2}}{V}\right) A_{3},
\end{aligned}
$$

$$
\begin{aligned}
\frac{d N_{n, 1}^{\prime}}{d t}= & \sum_{k} \chi_{k \rightarrow n} \lambda_{k} N_{k, 1}^{\prime}+\sum_{m} \sigma_{\gamma, m \rightarrow n} \phi I_{m, 1} \frac{N_{A}}{A_{m}} \\
& -k_{n, 1}\left(\frac{A_{n}}{A_{m}} \frac{N_{n, 1}^{\prime}}{I_{m, 1}} S_{m, 1}-\frac{N_{n, 2}^{\prime}}{V}\right) A_{1} \\
& -\left(\lambda_{n}+\sigma_{a, n} \phi\right) N_{n, 1}^{\prime},
\end{aligned}
$$

$$
\begin{aligned}
\frac{d N_{n, 2}^{\prime}}{d t}= & \sum_{k} \chi_{k \rightarrow n} \lambda_{k} N_{k, 2}^{\prime}+R \sum_{m} \sigma_{\gamma, m \rightarrow n} \phi I_{m, 2} \frac{N_{A}}{A_{m}} \\
& +k_{n, 1}\left(\frac{A_{n}}{A_{m}} \frac{N_{n, 1}^{\prime}}{I_{m, 1}} S_{m, 1}-\frac{N_{n, 2}^{\prime}}{V}\right) A_{1} \\
& -k_{n, 3}\left(\frac{N_{n, 2}^{\prime}}{V}-\frac{A_{n}}{A_{m}} \frac{N_{n, 3}^{\prime}}{I_{m, 3}} S_{m, 3}\right) A_{3} \\
& -\left(\lambda_{n}+R \sigma_{a, n} \phi\right) N_{n, 2}^{\prime}-\omega \frac{Q}{V_{\mathrm{CVCS}}} N_{n, 2}^{\prime},
\end{aligned}
$$

$$
\begin{aligned}
\frac{d N_{n, 3}^{\prime}}{d t}= & \sum_{k} \chi_{k \rightarrow n} \lambda_{k} N_{k, 3}^{\prime} \\
& +k_{n, 3}\left(\frac{N_{n, 2}^{\prime}}{V}-\frac{A_{n}}{A_{m}} \frac{N_{n, 3}^{\prime}}{I_{m, 3}} S_{m, 3}\right) A_{3} \\
& -\lambda_{n} N_{n, 3}^{\prime},
\end{aligned}
$$

where $I_{m, i}$ is the mass of nuclide $m$ in corrosion products, $\mathrm{kg}$, the subscript $i=1$ refers to the zone of in-flux pipe, $i=2$ refers to the zone of bulk coolant, and $i=3$ refers to the zone of out-flux pipe; $\mathrm{CR}_{i}$ is the corrosion rate of the base metal, $\mathrm{kg} /\left(\mathrm{m}^{2} \cdot \mathrm{s}\right) ; \alpha_{i}$ is the ratio of release rate to corrosion rate of the corrosion products, $\%$; $f_{m, i}$ is the mass fraction of 
nuclide $m$ in the base metal, \%; $A_{i}$ is the contact area between coolant and pipe, $\mathrm{m}^{2} ; k_{m, i}$ is the mass transfer coefficient of nuclide $m, \mathrm{~m} / \mathrm{s} ; V$ is the coolant volume in the cooling loop, $\mathrm{m}^{3} ; S_{m, i}$ is the solubility of nuclide $m$ in the coolant close to the pipe surface, $\mathrm{kg} / \mathrm{m}^{3} ; \omega$ is the collection efficiency of filter and resin in chemical and volume control system (CVCS), \%; $Q$ is the volume flow rate of coolant into CVCS, $\mathrm{m}^{3} / \mathrm{s} ; V_{\mathrm{CVCS}}$ is the coolant volume in CVCS, $\mathrm{m}^{3} ; N_{n, i}^{\prime}$ is the atom number of nuclide $n$ in ACPs, atoms, and the superscript ' means nuclide $n$ is radioactive; $\chi_{k \rightarrow n}$ is the decay branching ratio from nuclide $k$ to nuclide $n, \% ; \lambda_{k}$ is the decay rate constant of nuclide $k, \mathrm{~s}^{-1} ; \sigma_{\gamma, m \rightarrow n}$ is the radiative capture cross section of converting nuclide $m$ to nuclide $n, \mathrm{~cm}^{2} ; \phi$ is the neutron flux, $n /\left(\mathrm{cm}^{2} \cdot \mathrm{s}\right) ; A_{m}$ is the molar mass of nuclide $m, \mathrm{~kg} / \mathrm{mol} ; N_{A}$ is the Avogadro number; $\sigma_{a, n}$ is the absorption cross section of nuclide $n, \mathrm{~cm}^{2} ; R$ is the ratio of coolant residence time in the zone of in-flux pipe to that in the whole cooling loop, $\%$.

In the above model, some assumptions are made, including the following: (1) the concentration of nuclides in the coolant keeps the same along the cooling loop, which is because it takes the coolant only several seconds to circle around the cooling loop, which means the homogenization effect of nuclides in the coolant is dominant; (2) the influence of activation and decay on the mass of corrosion products is neglected because the quantity of ACPs is very limited compared to that of corrosion products; (3) the concentration of nuclides on the pipe surface is equal to its solubility in the adjacent coolant.

To solve the above differential equations, the fourth-order Runge-Kutta method is used, which is fast and can control the error well. Moreover, an algorithm of adaptive time step is adopted in CATE for determining the time step reasonably and the calculation speed can be improved.

\section{Verification of CATE Code through MIT PWR Coolant Chemistry Loop (PCCL)}

3.1. Description of MIT PCCL. MIT PCCL was chosen here to test the code CATE, which is a small scale loop operated under constant coolant chemistry in the MIT reactor to closely simulate the primary circuit of a typical PWR power plant. The main operation data of the loop is presented in Table 1 [5].

The base metal of in-flux pipe is Zircaloy- 4 and the corrosion rate of this material is nearly 0 . The base metal of out-flux pipe is mainly Inconel and the corrosion rate of it is $3.55 E-$ $7 \mathrm{~kg} /$ day.

3.2. Results of ACPs Radioactivity in MIT PCCL. The surveillance data from MIT PCCL for 42 days of full power operation was published, and the radioactivity of ACPs in the loop is as shown in Table 2.

Calculation results from CATE are close to the experimental results from MIT, which means CATE is available and credible on ACPs analysis of water-cooled nuclear reactor. The calculation results of mass of corrosion products in the in-flux pipe, the coolant, and the out-flux pipe are, respectively, $1.66 E-6 \mathrm{~kg}, 1.48 E-9 \mathrm{~kg}$, and $3.96 E-5 \mathrm{~kg}$ for CATE.
TABLE 1: The operation data of MIT PCCL.

\begin{tabular}{lc}
\hline Parameter & Value \\
\hline Temperature $\left({ }^{\circ} \mathrm{C}\right)$ & $273.9 \sim 315.6$ \\
Mass flow rate $(\mathrm{kg} / \mathrm{s})$ & $6.84 E-2$ \\
Flow velocity $(\mathrm{m} / \mathrm{s})$ & $2.83 \sim 3.18$ \\
Volume of coolant $\left(\mathrm{m}^{3}\right)$ & $3.84 E-4$ \\
Surface area of in-flux pipe $\left(\mathrm{m}^{2}\right)$ & $2.60 E-2$ \\
Surface area of out-flux pipe $\left(\mathrm{m}^{2}\right)$ & $9.70 E-2$ \\
Mass flow rate in CVCS $(\mathrm{kg} / \mathrm{s})$ & $5.34 E-5$ \\
Collection efficiency of CVCS & $50 \%$ \\
Concentration of boron $(\mathrm{ppm})$ & 800 \\
Concentration of $\mathrm{LiOH}(\mathrm{ppm})$ & 1.84 \\
Concentration of $\mathrm{H}_{2}\left(\mathrm{cc} / \mathrm{kg}-\mathrm{H}_{2} \mathrm{O}\right)$ & 25 \\
\hline
\end{tabular}

Using these data, we can calculate the specific radioactivity of ACPs in the in-flux pipe, the coolant, and the out-flux pipe, which is, respectively, $1.01 E+3 \mathrm{GBq} / \mathrm{kg}, 2.33 E+2 \mathrm{GBq} / \mathrm{kg}$, and $6.89 E+1 \mathrm{GBq} / \mathrm{kg}$ for CATE. The values are degressive, which is consistent with the transport direction of ACPs in the cooling loop and is rational.

\section{Calculation of ACPs Radioactivity in ITER Blanket Cooling Loop Using CATE Code}

4.1. Description of ITER Blanket Cooling Loop. The International Thermonuclear Experimental Reactor (ITER) is under construction now. In its design plan, the primary cooling loops are most water-cooled, such as the blanket, the divertor, the NB injector, and the vacuum vessel. So ITER can be treated as a representative of water-cooled fusion reactor. China is developing its own fusion reactor CFETR (China Fusion Engineering Test Reactor), whose design plan of heat transfer and radiation shielding partly refers to ITER, so ACPs analysis of ITER will benefit the work of source term control for CFETR.

The planned operation data of ITER blanket cooling loop is presented in Table 3 [6].

The base metal in in-flux pipe and out-flux pipe is the same kind of stainless steel, SS316, and the corrosion rate of it is as follows:

$$
\text { SS316: CR }=2.0 \times 10^{-5} \times t^{-0.614} \mathrm{~kg} \cdot \mathrm{m}^{-2} \cdot \mathrm{s}^{-1} .
$$

The above equation and the element composition of SS316 are quoted from [7]. The relevant nuclear reaction data are quoted from the European Activation File EAF-2007 [8, 9], and the cross section of activation reaction is collapsed from 172 groups into 1 group using the corresponding neutron spectrum, which is calculated with MCNP code [10] and based on an ITER blanket module [11]. The neutronics model and neutron spectrum of the chosen blanket module can be seen in Figures 2 and 3.

\subsection{Results of ACPs Radioactivity in ITER Blanket Cooling} Loop. After 1.2 years of full power operation, the mass of corrosion products and the radioactivity of ACPs in the loop are as shown in Table 4. 
TABLE 2: Radioactivity of ACPs in MIT PCCL after normal operation for 42 days.

\begin{tabular}{|c|c|c|c|c|c|c|}
\hline \multirow{3}{*}{ Data source } & \multicolumn{6}{|c|}{ Radioactivity of ACPs (GBq) } \\
\hline & \multicolumn{2}{|c|}{ In-flux pipe } & \multicolumn{2}{|c|}{ Coolant } & \multicolumn{2}{|c|}{ Out-flux pipe } \\
\hline & Co-58 & Co-60 & Co-58 & Co-60 & Co-58 & Co-60 \\
\hline MIT & $1.79 E-3$ & $1.16 E-4$ & $3.65 E-7$ & $2.43 E-8$ & $2.71 E-3$ & $1.95 E-4$ \\
\hline CATE & $1.51 E-3$ & $1.72 E-4$ & $3.09 E-7$ & $3.54 E-8$ & $2.44 E-3$ & $2.87 E-4$ \\
\hline
\end{tabular}

TABLE 3: The planned operation data of ITER blanket cooling loop.

\begin{tabular}{lc}
\hline Parameter & Value \\
\hline Temperature $\left({ }^{\circ} \mathrm{C}\right)$ & $140 \sim 174$ \\
Mass flow rate $(\mathrm{kg} / \mathrm{s})$ & 851 \\
Average flow velocity $(\mathrm{m} / \mathrm{s})$ & 4.0 \\
Volume of coolant $\left(\mathrm{m}^{3}\right)$ & 33.36 \\
Surface area of in-flux pipe $\left(\mathrm{m}^{2}\right)$ & 991.4 \\
Surface area of out-flux pipe $\left(\mathrm{m}^{2}\right)$ & 1395.1 \\
Mass flow rate in CVCS $(\mathrm{kg} / \mathrm{s})$ & 2.55 \\
Collection efficiency of CVCS & $50 \%$ \\
Concentration of $\mathrm{H}_{2}\left(\mathrm{cc} / \mathrm{kg}-\mathrm{H}_{2} \mathrm{O}\right)$ & 25 \\
\hline
\end{tabular}

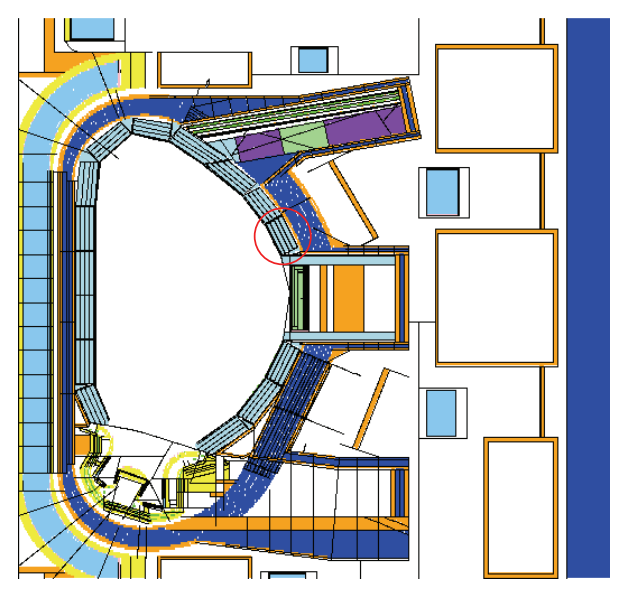

FIgURE 2: The neutronics model of the chosen blanket module (marked with a red ring).

From Table 4, we can see that mass of corrosion products in the coolant is much lower than that on the pipe surface, which is due to the limitation of solubility of corrosion products in the coolant. It should be noticed that the corrosion products on the pipe surface include oxides and deposits. The oxides are compact and fixed, while the deposits are loose and mobilizable and their mass is usually one order of magnitude lower than that of oxides. So, although the total mass of corrosion products on the pipe surface is tens of $\mathrm{kg}$, the actual mass of deposits is only in the magnitude of $\mathrm{kg}$, which is consistent with the experience in safety analysis.

We also can see that ACPs radioactivity on the pipe surface is much higher than that in the coolant, which means the pipe surface is the main radioactive contamination region and should be decontaminated regularly through water chemistry method. The specific radioactivity of ACPs in the in-flux pipe, the coolant, and the out-flux pipe is calculated as
TABLE 4: Calculation results of ACPs in ITER blanket cooling after normal operation for 1.2 years from CATE.

\begin{tabular}{lccc}
\hline & In-flux pipe & Coolant & Out-flux pipe \\
\hline $\begin{array}{l}\text { Mass of corrosion } \\
\text { products }(\mathrm{kg})\end{array}$ & $2.17 E+1$ & $6.25 E-3$ & $2.66 E+1$ \\
$\begin{array}{l}\text { Radioactivity of ACPs } \\
(\mathrm{GBq})\end{array}$ & $1.05 E+6$ & $2.77 E+0$ & $8.90 E+3$ \\
\hline
\end{tabular}

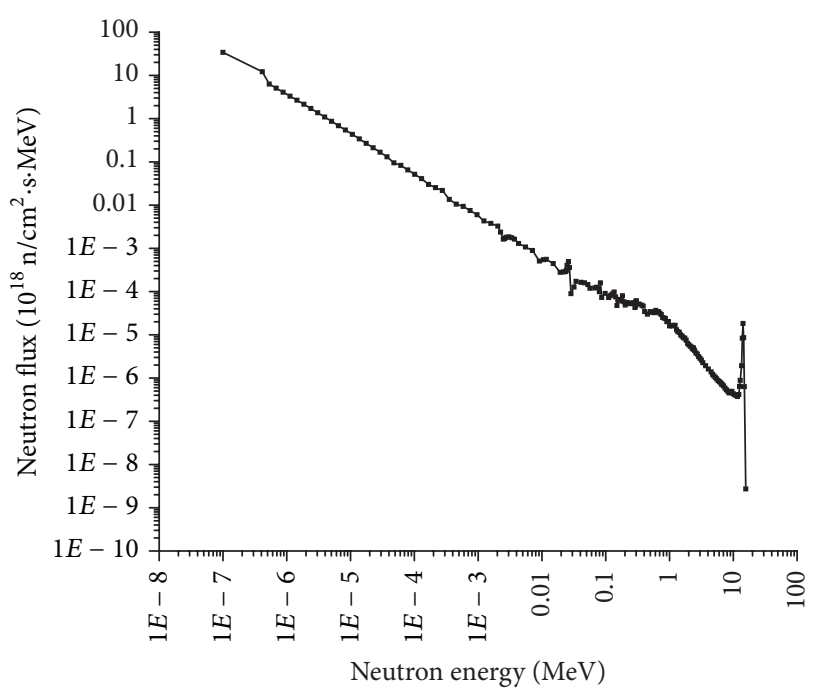

FIGURE 3: The neutron spectrum of the chosen blanket module.

$4.84 E+4 \mathrm{GBq} / \mathrm{kg}, 4.43 E+2 \mathrm{GBq} / \mathrm{kg}$, and $3.35 E+2 \mathrm{GBq} / \mathrm{kg}$. The values are degressive, which is consistent with the transport direction of ACPs in the cooling loop and is rational.

From Table 5, we can see that the short-life nuclides (V-52, V-53, Cr-55, Mn-56, Co-58m, Co-60m, and Ni-57) are the major contributors to radioactivity in all the three regions, especially $\mathrm{Mn}-56$, which alone contributes $63.33 \%$ of the radioactivity in the region of in-flux pipe and nearly $80 \%$ of the radioactivity in the regions of coolant and out-flux pipe. That is very different from PWR, in which the long-life nuclides Co-58 and Co-60 are the main ACPs. And when the reactor shuts down for a period of time (about several days), ACPs radioactivity will decrease obviously due to the rapid decay of the short-life nuclides, and then the right time for workers to do maintenance comes. 
TABLE 5: The main ACPs after normal operation for 1.2 years from CATE.

\begin{tabular}{lcccc}
\hline \multirow{2}{*}{ Nuclide } & \multirow{2}{*}{ Half-life } & \multicolumn{3}{c}{ Radioactivity $(\mathrm{GBq})$} \\
& & In-flux pipe & Coolant & Out-flux pipe \\
\hline V-49 & $330 \mathrm{~d}$ & $4.04 E+2$ & $5.07 E-7$ & $4.14 E-6$ \\
V-52 & $3.74 \mathrm{~m}$ & $1.03 E+4$ & $7.81 E-3$ & $2.69 E+0$ \\
V-53 & $1.6 \mathrm{~m}$ & $5.95 E+2$ & $4.27 E-4$ & $6.68 E-2$ \\
Cr-51 & $27.7 \mathrm{~d}$ & $2.35 E+5$ & $3.21 E-1$ & $8.48 E+2$ \\
Cr-55 & $3.50 \mathrm{~m}$ & $3.78 E+3$ & $2.85 E-3$ & $9.33 E-1$ \\
Mn-56 & $2.58 \mathrm{~h}$ & $6.59 E+5$ & $2.15 E+0$ & $7.07 E+3$ \\
Fe-55 & $2.74 \mathrm{y}$ & $4.04 E+4$ & $2.09 E-1$ & $7.67 E+2$ \\
Fe-59 & $44.5 \mathrm{~d}$ & $4.79 E+3$ & $1.08 E-2$ & $3.47 E+1$ \\
Co-57 & $272 \mathrm{~d}$ & $1.67 E+4$ & $1.98 E-2$ & $6.08 E+1$ \\
Co-58m & $9.04 \mathrm{~h}$ & $2.72 E+4$ & $1.31 E-2$ & $5.79 E-1$ \\
Co-58 & $70.9 \mathrm{~d}$ & $3.79 E+4$ & $3.67 E-2$ & $9.44 E+1$ \\
Co-60m & $10.5 \mathrm{~m}$ & $2.94 E+3$ & $1.34 E-3$ & $2.36 E-3$ \\
Co-60 & $5.27 \mathrm{y}$ & $3.69 E+2$ & $9.04 E-4$ & $3.22 E+0$ \\
Ni-57 & $35.6 \mathrm{~h}$ & $1.57 E+3$ & $6.24 E-4$ & $5.51 E-2$ \\
Ni-63 & $100 \mathrm{y}$ & $5.71 E+2$ & $7.41 E-4$ & $2.41 E+0$ \\
\hline Total & & $1.04 E+6$ & $2.77 E+0$ & $8.89 E+3$ \\
Short-lived & & $7.06 E+5$ & $2.17 E+0$ & $7.07 E+3$ \\
\hline
\end{tabular}

\section{Calculation of Dose Rate Caused by ACPs Using ARShield Code}

The ARShield code developed by NCEPU of China is applied to dose rate calculation, which is a new version of the point kernel integration code QAD-CG developed by Los Alamos National Laboratory. ARShield breaks some restrictions of QAD-CG, such as complicated modeling, complicated source setting, 3D fine mesh results statistics, and large-scale computing efficiency, and is proved to be reliable and efficient on dose rate calculation.

The density of each radionuclide at chosen regions calculated by CATE is introduced into ARShield and then converted to dose rate using point kernel integration method, which is as follows:

$$
\begin{aligned}
& D(r) \\
& =\int_{V} \frac{K s\left(r^{\prime}\right) B\left(\mu\left|r \longrightarrow r^{\prime}\right|, E\right) \exp \left(-\mu\left|r \longrightarrow r^{\prime}\right|\right) d V}{2 \pi\left|r \longrightarrow r^{\prime}\right|^{2}},
\end{aligned}
$$

where $r$ is the point at which gamma dose rate is to be calculated; $r^{\prime}$ is the location of source in volume $V ; V$ is the volume of source region; $\mu$ is the total attenuation coefficient at energy $E ;\left|r \rightarrow r^{\prime}\right|$ is the distance between source point and point at which gamma intensity is to be calculated; $K$ is the flux-to-dose conversion factor; $B$ is the dose buildup factor.

The geometry of hot leg pipe in ITER blanket cooling loop is adopted to represent the region of out-flux pipe, which has an internal diameter of $0.527 \mathrm{~m}$, thickness of $0.02 \mathrm{~m}$, and length of $33 \mathrm{~m}$. The dose rate around the hot leg pipe calculated by ARShield is shown in Figure 4.

We can see that after shutting down the reactor for 8 days, the dose rate is much lower than that of normal operation for

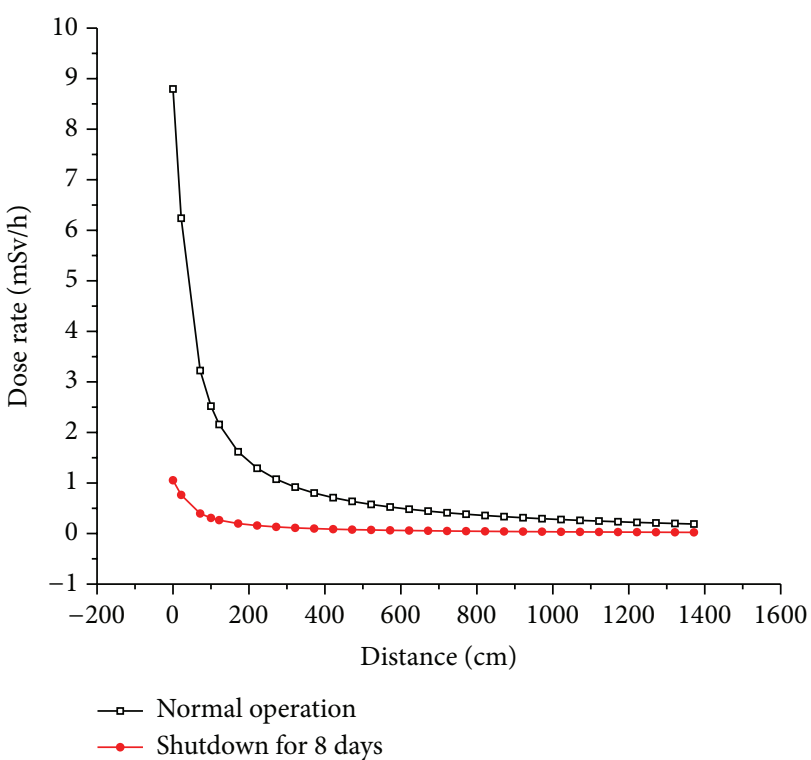

FIGURE 4: Variation of dose rate with the distance from the outer surface of the hot leg pipe.

1.2 years, which is because that contribution from the shortlife ACPs decreases almost to zero after shutdown for 8 days. The typical values of dose rate are as follows: during normal operation, the dose rate at the outer surface of the pipe is $8.80 \mathrm{mSv} / \mathrm{h}$, and the dose rate at a distance $1 \mathrm{~m}$ away from the outer surface of the pipe is $2.52 \mathrm{mSv} / \mathrm{h}$; after shutdown for 8 days, the values drop to $1.05 \mathrm{mSv} / \mathrm{h}$ (contact) and $0.31 \mathrm{mSv} / \mathrm{h}$ ( $1 \mathrm{~m}$ away). When these values are compared to the annual permissible worker dose rate of $20 \mathrm{mSv} /$ year, recommended by the ICRP [12], the contact dose rate value after shutdown for 8 days would allow approximately $19 \mathrm{~h}$ exposure per year.

\section{Conclusions}

In this paper, a three-node transport model was introduced into the ACPs source term code CATE, making CATE capable of theoretically simulating the variation and the distribution of ACPs in a water-cooled reactor and suitable for more operating conditions. MIT PCCL was chosen to test the new version of CATE, and the calculation results from CATE are close to the experimental results from MIT, which means CATE is available and credible on ACPs analysis of water-cooled reactor. Then the radioactivity and composition of ACPs in ITER blanket cooling loop were analyzed using CATE and the results showed that the major contributors are the short-life nuclides (V-52, V-53, Cr-55, Mn-56, Co-58m, Co-60m, and Ni-57) for ITER, especially Mn-56. That is very different from PWR, in which the long-life nuclides Co-58 and Co-60 are the main ACPs. At last, the dose rate around ITER blanket cooling loop caused by ACPs was calculated through coupling the code CATE with a point kernel integration code ARShield. The results showed that after shutting down the reactor only for 8 days, the dose rate can decrease nearly one order of magnitude compared to that of normal operation, which is caused by the rapid decay of the short-life ACPs. In 
the future, CATE will be applied for ACPs analysis of Chinese water-cooled fusion reactor CFETR as soon as its design plan is completed.

\section{Competing Interests}

The authors declare that they have no competing interests.

\section{Acknowledgments}

This work was sponsored jointly by "National Special Project for Magnetic Confined Nuclear Fusion Energy" with Grant no. 2014GB119000 and the "Fundamental Research Funds for the Central Universities" with Grant no. 2014QN26 in China. The authors would like to express their gratitude for the support.

\section{References}

[1] A. Rocher, J. L. Bretelle, and M. Berger, "Impact of main radiological pollutants on contamination risks (ALARA) optimization of physico chemical environment and retention technics during operation and shutdown," in Proceedings of the European Workshop on Occupational Exposure Management at NPPs (ISOE '04), Session 2, EDF, Lyon, France, March 2004.

[2] M. Rafique, N. M. Mirza, S. M. Mirza, and M. J. Iqbal, "Review of computer codes for modeling corrosion product transport and activity build-up in light water reactors," Nukleonika, vol. 55, no. 3, pp. 263-269, 2010.

[3] L. Li, J. Zhang, W. Song, Y. Fu, X. Xu, and Y. Chen, "CATE: a code for activated corrosion products evaluation of watercooled fusion reactor," Fusion Engineering and Design, vol. 100, pp. 340-344, 2015.

[4] IAEA, "Modelling of transport of radioactive substances in the primary circuit of water-cooled reactors," IAEA-TECDOC1672, 2012.

[5] C. B. Lee, Modeling of Corrosion Product Transport in PWR Primary Coolant, Nuclear Engineering Department, MIT, 1990.

[6] S. Nisan, L. D. Pace, and J.-C. Robin, "Evaluation of the activated corrosion products for the ITER heat transfer systems," in Fusion Technology, pp. 1763-1766, Elsevier, 1996.

[7] P. J. Karditsas, "Activation product transport using TRACT: ORE estimation of an ITER cooling loop," Fusion Engineering and Design, vol. 45, no. 2, pp. 169-185, 1999.

[8] R. A. Forrest, J. Kopecky, and J.-Ch. Sublet, "The European Activation File: EAF-2007 neutron-induced cross section library," UKAEA FUS 535, 2007.

[9] R. A. Forrest, “The European Activation File: EAF-2007 decay data library," UKAEA FUS 537, 2007.

[10] J. F. Briesmeister, MCNP: a general Monte Carlo N-particle transport code version 4C, Los Alamos National Laboratory, LA-13709-M, 2000.

[11] H. Iida, V. Khripunov, and L. Petrizzi, "Nuclear analysis report," ITER Document NAG-201-01-06-17-FDR, 2001.

[12] ICRP, "Recommendations of the international commission on radiological protection, publication 60," Annals of the ICRP 21, Pergamon Press, Oxford, UK, 1991. 

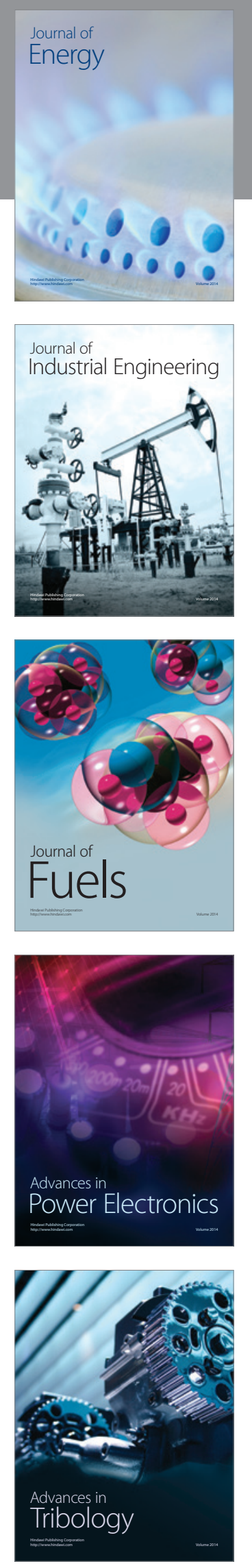
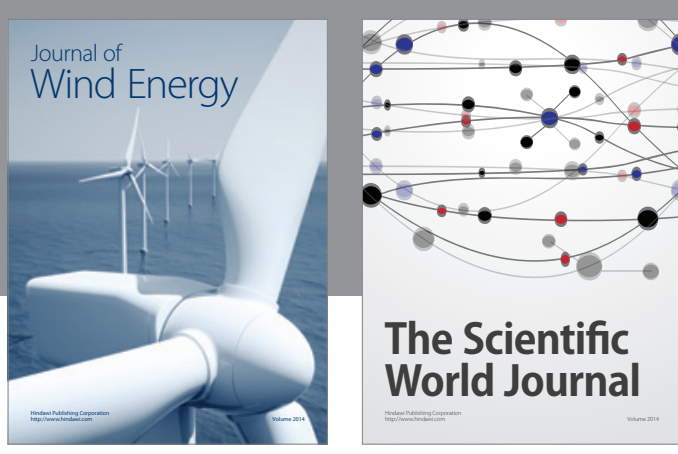

The Scientific World Journal
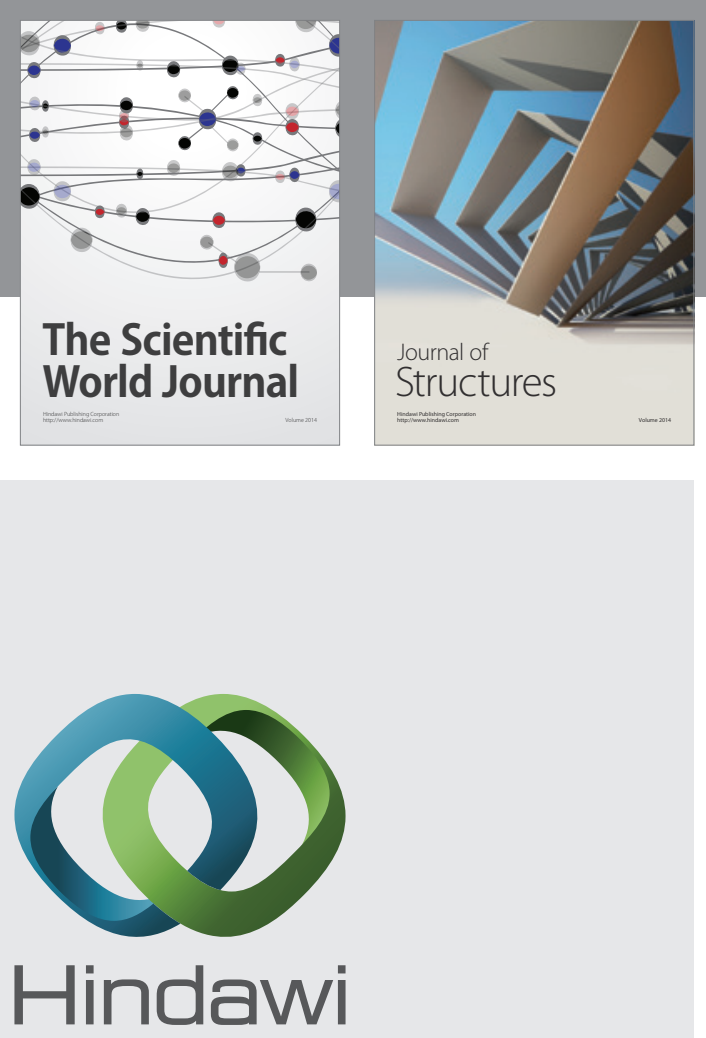

Submit your manuscripts at

http://www.hindawi.com
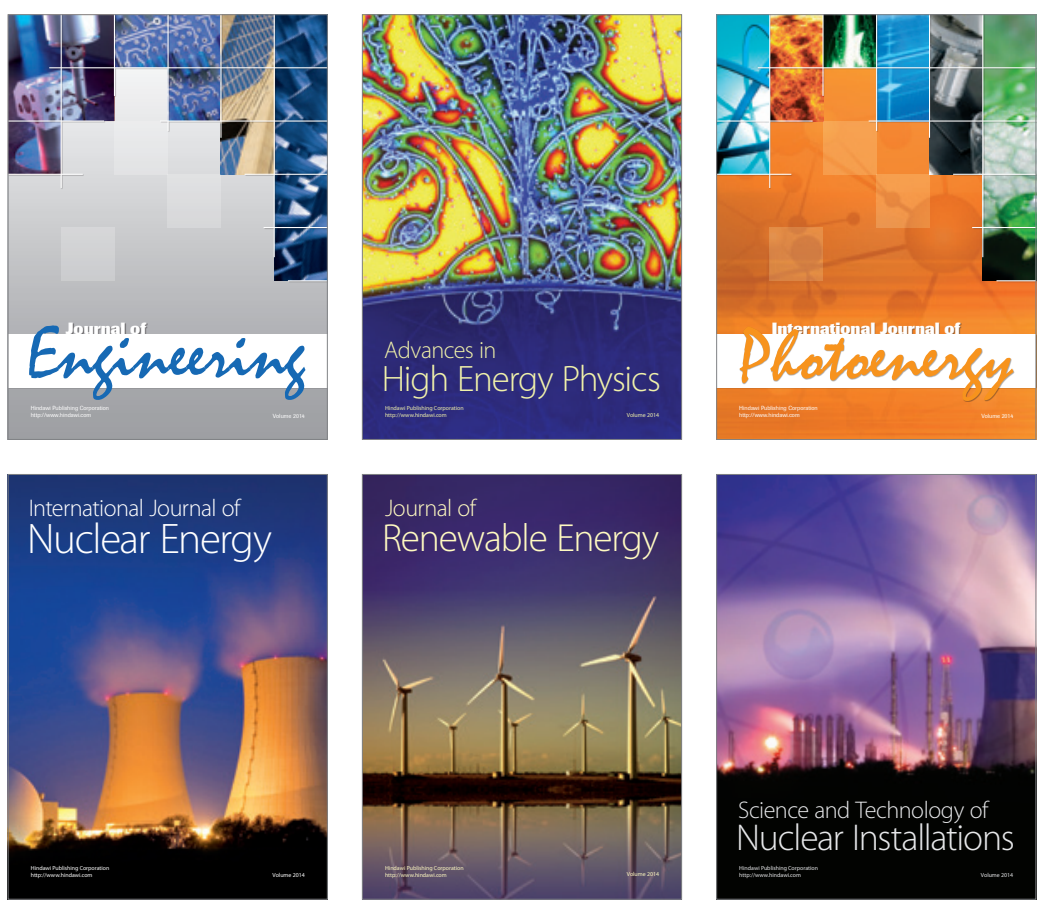
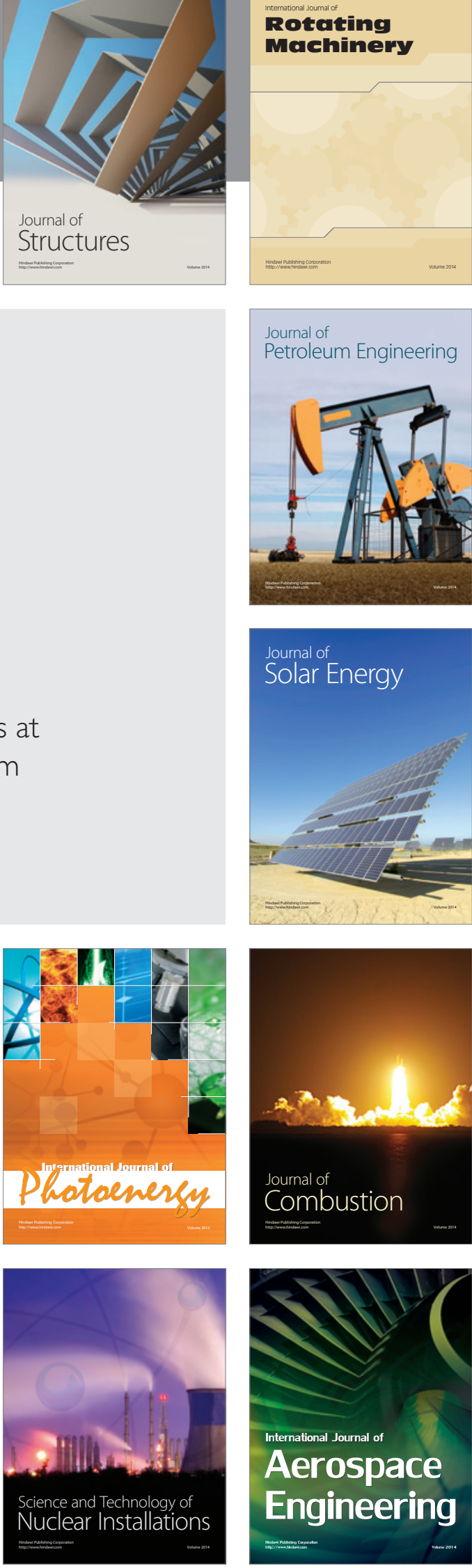